\title{
A meta-analysis of cancer risk associated with the TP53 intron 3 duplication polymorphism (rs17878362): geographic and tumor-specific effects
}

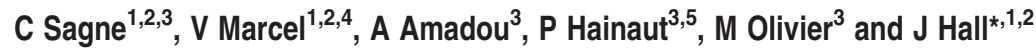

We have performed a meta-analysis of cancer risk associated with the rs 17878362 polymorphism of the TP53 suppressor gene (PIN3, (polymorphism in intron 3), 16 bp sequence insertion/duplication in intron 3), using a compilation of a total of 25 published studies with 10786 cases and 11760 controls. Homozygote carriers of the duplicated allele (A2A2) had a significantly increased cancer risk compared with $\mathrm{A} 1 \mathrm{~A} 1$ carriers (aggregated odds ratio $(\mathrm{OR})=1.45,95 \%$ confidence interval $(\mathrm{Cl})=1.22-1.74)$. However, there was no significant effect for the $A 1 A 2$ heterozygotes (A1A2 versus $A 1 A 1$ aggregated $O R=1.08,95 \% \mathrm{Cl}=0.99-1.18$ ). No significant heterogeneity or publication bias was detected in the data set analysed. When comparing populations groups, increased cancer risk was associated with A2A2 carriage in Indian, Mediterranean and Northern Europe populations but not in the Caucasian population of the United States. Analysis by cancer site showed an increased risk for A2A2 carriers for breast and colorectal, but not for lung cancers. These results support that the A2A2 genotype of rs17878362 is associated with increased cancer risk, with population and tumour-specific effects.

Cell Death and Disease (2013) 4, e492; doi:10.1038/cddis.2013.24; published online 14 February 2013

Subject Category: Cancer

The TP53 gene (OMIM 191170), encoding the p53 protein, is frequently inactivated in sporadic human tumours, disabling a wide range of anti-proliferative responses regulating cell cycle progression, apoptosis, autophagy, differentiation, senescence, DNA repair and oxidative metabolism. ${ }^{1-4}$ The activity of p53 is regulated by multiple transcriptional, post-transcriptional, translational and post-translational mechanisms in response to a wide range of physical and biological stresses, endowing this protein with a pivotal role in preventing DNA replication and cell division in conditions that threaten genetic integrity. ${ }^{1,5-7}$ Among these mechanisms, the expression of p53 as multiple protein isoforms with different $\mathrm{N}$ - and/or $\mathrm{C}$-terminal domains has recently emerged as a form of regulation that may participate in the diversity of the repertoire of biological effects mediated by p53 (reviewed in Marcel et a $\beta^{\beta}$ ).

Close to 100 genetic polymorphisms have been identified in TP53 (listed at http://p53.iarc.fr), ${ }^{9}$ many of which show geographic and population frequency variations. However, their effects on cancer risk appear to be inconsistent across studies. ${ }^{10,11}$ The most studied polymorphism is a single-nucleotide polymorphism (SNP) in exon 4 encoding an arginine $(\mathrm{R})$ or a proline $(\mathrm{P})$ at codon 72 (rs1042522, $\mathrm{G}>\mathrm{C}, \mathrm{R}>\mathrm{P}$ at codon 72 , PEX4 (polymorphism in exon 4 )). ${ }^{12}$
There is in vitro evidence that the rs $1042522 \mathrm{R} 72$ and P72 p53 protein variants differ by their biological activities. ${ }^{13,14}$ However, results from systematic studies and meta-analyses have failed to identify a consistent association with cancer risk. ${ }^{15-19}$

The most common intronic variation in TP53 is a 16-base pair (bp) ${ }^{11}$ insertion/duplication in intron 3 (rs17878362, consisting of one copy (A1 allele) or two copies (A2 allele) of the sequence ACCTGGAGGGCTGGGG, PIN3 (polymorphism in intron 3 (rs17878362))). ${ }^{20}$ Several case-control studies have reported an increased risk of various cancer types associated with the rs17878362 A2 allele in Caucasians, with the most consistent association reported for breast, ${ }^{21,22}$ and colorectal cancers. ${ }^{23,24} \mathrm{~A}$ recent meta-analysis identified a small but significant increase in overall cancer risk of $14 \%$ (95\% confidence interval $(\mathrm{Cl})=1.02-1.27)$ in homozygote carriers of the A2 allele. ${ }^{25}$ However, this conclusion was questioned because of apparent discrepancies between data selected for meta-analysis and the original publications. ${ }^{26}$ At the mechanistic level, there is some evidence that rs17878362 may have an impact on the levels ${ }^{23}$ and alternative splicing of the TP53 mRNA, and thus on the ratios of p53 protein isoforms. ${ }^{8}$ However, the precise mechanisms underlying an increased cancer risk associated with the rs17878362 A2 allele are not clearly understood.

\footnotetext{
${ }^{1}$ INSERM U612, Bât 110-112, Centre Universitaire, Orsay, France; ${ }^{2}$ Institut Curie, Centre de Recherche, Bât 110-112, Centre Universitaire, Orsay, France and ${ }^{3}$ Molecular Carcinogenesis Group, International Agency for Research on Cancer, 150 cours Albert Thomas, Lyon, France

*Corresponding author: Dr J Hall, Institut Curie, Centre de Recherche, INSERM U612, Bât 110-112, Centre Universitaire, Orsay 91405, France.

Tel: + 33 (0)1 698630 61; Fax: + 33 (0)1 690753 27; E-mail: janet.hall@ curie.fr

${ }^{4}$ Present address: Cancer Research Centre of Lyon, UMR INSERM 1052 CNRS 5286, Centre Léon Bérard, FNCLCC, Nuclear Domains and Pathologies, 28 rue Laennec, 69373 Lyon, France.

${ }^{5}$ Present address: International Prevention Research Institute, 95 cours Lafayette, 69006 Lyon, France.

Keywords: TP53; rs17878362; intron3; PIN3

Abbreviations: Bp, base pair; Cl, confidence interval; MAF, minor allele frequency; OR, odds ratio; PEX4, polymorphism in exon 4 (rs1042522); PIN3, polymorphism in intron 3 (rs17878362); PIN6, polymorphism in intron 6 (rs1625895); SNP, single-nucleotide polymorphism

Received 08.10.12; revised 18.12.12; accepted 21.12.12; Edited by A Stephanou
} 
To assess whether the rs17878362 polymorphism may represent a potentially important and relevant genetic marker contributing to cancer susceptibility, we have performed an independent, two-stage meta-analysis on a total of 10786 cancer cases and 11377 controls from 25 published case-control studies. First, we have analysed the overall cancer risk associated with the A2 allele and second we have performed sub-group analyses to examine this association in different populations and for specific cancer types. Data for the rs1042522 and rs1625895 (rs1625895, intron 6, G $>$ A, PIN6 (polymorphism in intron 6)) variant alleles in relation to cancer risk was also compiled and analysed from the same publication set to assess their potential confounding effect.

\section{Results}

Characteristics of selected publications. A total of 25 publications out of the 299 identified met the necessary inclusion criteria for the meta-analysis that required the reporting of odds ratio (OR) data and information on the frequency of each allele, which has been verified to be in Hardy-Weinberg equilibrium in each control population (Table 1 and Supplementary Table 1). Two studies ${ }^{24,27}$ used the same control populations and they were included only once to avoid over-representation. Overall, nine individual studies reported a significant increase in cancer risk associated with the rs17878362 A2 allele compared with the A1 allele, 16 showed no statistical association between either allele and cancer susceptibility and no study reported an association between the A2 allele and decreased cancer risk (Table 1).

The A2A2 genotype of rs17878362 polymorphism increases cancer risk. On the basis of the results of the heterogeneity testing, a random model was used for the meta-analysis to assess the overall cancer risk in $A 2$ allele carriers (A1A2 or A2A2) (Table 2). ${ }^{28}$ The rs17878362 minor allele frequency (MAF) was inferior to 0.17 in control subjects in the different sub-groups and allele ratios were compatible with Hardy-Weinberg equilibrium (data not presented). No significant association with cancer risk was found in the heterozygous $A 1 A 2$ carriers compared with the homozygous $\mathrm{A} 1 \mathrm{~A} 1$ carriers (A1A2 versus $\mathrm{A} 1 \mathrm{~A} 1$ aggregated $\mathrm{OR}=1.08$, $95 \% \mathrm{Cl}=0.99-1.18)$, however, a significantly increased risk was found for the A2A2 carriers (A2A2 versus A1A1 aggregated $\mathrm{OR}=1.45,95 \% \mathrm{Cl}=1.22-1.74)$. Leave-oneout analyses showed that the aggregated OR for the A1A2 versus $A 1 A 1$ genotypes varied between 1.06 and $1.10(95 \%$ $\mathrm{Cl}$ between 0.97 and 1.20) and for the $\mathrm{A} 2 \mathrm{~A} 2$ versus $\mathrm{A} 1 \mathrm{~A} 1$ genotypes between 1.37 and 1.55 (95\% Cl between 1.15 and 1.91) (Supplementary Table 2). The Egger's bias coefficient was determined to assess a possible bias introduced by any single study. The ORs for Egger's bias coefficient were 0.07 , $(95 \% \mathrm{Cl}=1.32-1.46)$ for the $\mathrm{A} 1 \mathrm{~A} 2$ genotype, and $0.79(95 \%$ $\mathrm{Cl}=0.62-2.19)$ for the $\mathrm{A} 2 \mathrm{~A} 2$ genotype, suggesting no significant publication bias.

To assess the possibility that the overall result might be biased by initial publications reporting a large effect, a cumulative inclusion over time analysis was conducted. For the A1A2 genotype, the first set of studies (four reports published before 2006) had the highest ORs for the association between the $\mathrm{A} 1 \mathrm{~A} 2$ genotype and cancer risk (Supplementary Table 3). Lower values were reported in the following 2 years, after which the overall result remained stable (aggregated OR 1.08 for 2010 and 2011). For the A2A2 allele, the time trend for the aggregated OR showed little variation, with ORs between 1.37 and 1.45 being reported since 2007, in support of the robustness of this association.

rs17878362-related cancer risk is dependent on ethnicity and geographical origin. To investigate whether rs17878362 related cancer susceptibility varies between populations and geographical regions, the data from the 25 studies were divided into four geographical sub-groups (India, Northern Europe, North America and the Mediterranean area) each containing at least 1000 cases and 1000 controls from a minimum of five independent case-control studies (Table 2, see Table 1 and Supplementary Table 1 for population details). Differences in genotype distribution were noted with that of the Indian controls being statistically different from the three other control sub-groups (India versus Mediterranean countries: $\chi^{2} P$-value 0.01 , India versus Northern Europe or United States: $\chi^{2} P$-values $<0.01)$. The genotype distribution found in the United States' controls (reported as a Caucasian population in the original publications) was also different from that of the Northern Europe controls ( $\chi^{2} P$-value 0.01). No difference in genotype distribution was observed between controls from the Mediterranean and from Northern Europe or United States (Mediterranean countries versus Northern Europe: $\chi^{2}$ $P$-value 0.49 , Mediterranean countries versus United States: $\chi^{2} P$-value 0.14).

In this geographical sub-group analysis, the homozygous A2A2 genotype was associated with an increased cancer risk in Indian (A2A2 versus A1A1 aggregated OR $=1.63,95 \%$ $\mathrm{Cl}=1.10-2.42)$ and Northern Europe populations (A2A2 versus $A 1 A 1$ aggregated $O R=1.70,95 \% \mathrm{Cl}=1.26-2.31$ ) compared with the homozygous $\mathrm{A} 1 \mathrm{~A} 1$ genotype. For the Mediterranean population, both the A1A2 and A2A2 genotypes were associated with increased cancer susceptibility in an $\mathrm{A} 2$ allelic dose-dependent manner (A1A2 versus $\mathrm{A} 1 \mathrm{~A} 1$ aggregated $\mathrm{OR}=1.25,95 \% \mathrm{Cl}=1.03-1.51 ; \mathrm{A} 2 \mathrm{~A} 2$ versus $\mathrm{A} 1 \mathrm{~A} 1$ aggregated $\mathrm{OR}=2.54,95 \% \mathrm{Cl}=1.53-4.24, P$-trend $<0.01)$. In contrast, in the United States' sub-group $(3,963$ cases and 3,731 controls), no increased cancer susceptibility was associated with carriage of the rs17878362 A2 allele $(\mathrm{A} 1 \mathrm{~A} 2$ versus $\mathrm{A} 1 \mathrm{~A} 1$ aggregated $\mathrm{OR}=1.09,95 \%$ $\mathrm{Cl}=0.87-1.38 ; \mathrm{A} 2 \mathrm{~A} 2$ versus $\mathrm{A} 1 \mathrm{~A} 1$ aggregated $\mathrm{OR}=1.02$, $95 \% \mathrm{Cl}=0.73-1.43)$.

rs17878362-related cancer risk is dependent on cancer type. The risk of developing cancer was assessed for three cancer types: lung, colon and breast, with over 1600 cases and controls included in the analysis (Table 3). For colorectal cancer, homozygous A2A2 carriage was associated with increased susceptibility compared with homozygous $\mathrm{A} 1 \mathrm{~A} 1$ carriage (A2A2 versus $\mathrm{A} 1 \mathrm{~A} 1$ aggregated 
Table 1 Characteristics of the 25 case-control studies selected for TP53 rs17878362 (PIN3) polymorphism meta-analysis

\begin{tabular}{|c|c|c|c|c|c|c|c|c|c|c|c|}
\hline \multicolumn{2}{|c|}{ Study numbers and study } & \multirow[t]{2}{*}{$\begin{array}{c}\text { Cancer } \\
\text { type }\end{array}$} & \multirow[t]{2}{*}{ Cases } & \multirow[t]{2}{*}{ Controls } & \multirow[t]{2}{*}{ Population } & \multicolumn{3}{|c|}{$\begin{array}{l}\text { Minor allele frequency in } \\
\text { controls (MAF) }\end{array}$} & \multicolumn{3}{|c|}{$\begin{array}{c}\text { Hardy-Weinberg equilibrium } \\
P \text {-value for controls }\end{array}$} \\
\hline & & & & & & $\begin{array}{l}\text { rs } 17878362 \\
\text { (A2) }\end{array}$ & $\begin{array}{l}\text { rs } 1042522 \\
\quad(P 72)\end{array}$ & $\begin{array}{l}\text { rs1625895 } \\
\text { (A) }\end{array}$ & $\begin{array}{l}\text { rs17878362 } \\
\text { (A2) }\end{array}$ & $\begin{array}{l}\text { rs1042522 } \\
\text { (P72) }\end{array}$ & $\begin{array}{l}\text { rs1625895 } \\
\text { (A) }\end{array}$ \\
\hline 1 & Jha et $a l^{40 \text { a }}$ & Glial tissue & 84 & 76 & India & 0.18 & 0.55 & NA & 0.23 & $0.01^{b}$ & NA \\
\hline 2 & Umar et al. ${ }^{41 \mathrm{a}}$ & Oesophagus & 255 & 255 & India & 0.19 & NA & NA & 0.33 & NA & NA \\
\hline 3 & Alawadi et al. ${ }^{42 \text { a }}$ & Breast & 229 & 133 & NC & 0.31 & 0.44 & NA & 0.58 & $0.01^{b}$ & NA \\
\hline 4 & Mittal et al. ${ }^{43}$ a & Prostate & 177 & 265 & India & 0.15 & 0.24 & 0.21 & 0.12 & 0.28 & 0.11 \\
\hline 5 & Malik et al..$^{27 \mathrm{c}}$ & Oesophagus & 135 & $\mathrm{~d}_{195}$ & India & 0.21 & NA & NA & 0.08 & NA & NA \\
\hline 6 & Malik et al. ${ }^{27 \mathrm{c}}$ & Gastric & 108 & $\mathrm{~d}_{195}$ & India & 0.21 & NA & NA & 0.08 & NA & NA \\
\hline 7 & Naccarati et al. 44 a & Pancreas & 240 & 743 & Northern Europe & 0.16 & 0.29 & NA & 0.10 & 0.40 & NA \\
\hline 8 & Polakova et al. ${ }^{45 \mathrm{a}}$ & Colon & 612 & 613 & Northern Europe & 0.14 & 0.27 & NA & 0.15 & 0.52 & NA \\
\hline 9 & Ashton et $a l^{30}$ a & Endometrial & 190 & 291 & NC & 0.14 & 0.24 & 0.11 & 0.81 & 0.97 & 0.12 \\
\hline 10 & de Feo et al. ${ }^{46 \text { a }}$ & Gastric & 114 & 295 & Mediterranean & 0.16 & 0.25 & 0.20 & 0.35 & 0.13 & 0.15 \\
\hline 11 & Hrstka et al. ${ }^{47}$ a & Breast & 117 & 108 & Northern Europe & 0.14 & 0.45 & 0.13 & 0.46 & $0.00^{\mathrm{b}}$ & 0.78 \\
\hline 12 & Gaudet et al. ${ }^{48 \mathrm{a}}$ & Breast & 578 & 390 & United States & 0.16 & 0.74 & 0.85 & 0.85 & 0.08 & 0.93 \\
\hline 13 & Costa et al. ${ }^{21 \mathrm{c}}$ & Breast & 191 & 216 & Mediterranean & 0.17 & 0.17 & NA & 0.29 & 0.29 & NA \\
\hline 14 & Ye et al. ${ }^{49 \mathrm{a}}$ & Bladder & 636 & 618 & United States & 0.15 & 0.22 & 0.15 & 0.29 & $0.00^{\mathrm{b}}$ & 0.13 \\
\hline 15 & de Vecchi et al..$^{50 a}$ & Breast & 350 & 352 & Mediterranean & 0.15 & 0.23 & NA & 0.62 & 0.23 & NA \\
\hline 16 & Chen et al. ${ }^{51 \mathrm{a}}$ & $\begin{array}{l}\text { Head and } \\
\text { neck }\end{array}$ & 821 & 818 & United States & 0.14 & 0.27 & 0.12 & 0.75 & 0.07 & 0.67 \\
\hline 17 & Tan et al..$^{52 \mathrm{a}}$ & Colon & 467 & 563 & Northern Europe & 0.17 & 0.22 & NA & 0.23 & 0.98 & NA \\
\hline 18 & Wang et $a l^{53 \mathrm{a}}$ & Lung & 1412 & 1363 & United States & 0.13 & 0.26 & 0.12 & 0.45 & 0.54 & 0.14 \\
\hline 19 & Hung et al. ${ }^{54 \mathrm{c}}$ & Lung & 2126 & 2140 & Northern Europe & 0.13 & 0.27 & NA & 0.50 & 0.74 & NA \\
\hline 20 & Perfumo et al. 24 a & Colon & 60 & $188^{\mathrm{e}}$ & Mediterranean & 0.15 & 0.20 & NA & 0.21 & 0.81 & NA \\
\hline 21 & Perfumo et al. ${ }^{24 \mathrm{c}}$ & Colon & 124 & $188^{\mathrm{e}}$ & Mediterranean & 0.15 & 0.20 & NA & 0.21 & 0.81 & NA \\
\hline 22 & Mitra et al. ${ }^{55 \mathrm{a}}$ & Oral cancer & 307 & 342 & India & 0.19 & 0.48 & NA & 0.56 & 0.20 & NA \\
\hline 23 & Gemignani et al. ${ }^{23 \mathrm{c}}$ & Colon & 374 & 322 & Mediterranean & 0.12 & 0.21 & NA & 0.60 & 0.09 & NA \\
\hline 24 & Wang-Gohrke et al. ${ }^{22 \mathrm{c}}$ & Breast & 563 & 549 & Northern Europe & 0.16 & 0.26 & 0.15 & 0.92 & 0.49 & 0.60 \\
\hline 25 & Wu et al. ${ }^{56 \mathrm{c}}$ & Lung & 516 & 542 & United States & 0.10 & 0.20 & 0.12 & 0.05 & $0.01^{\mathrm{b}}$ & 0.18 \\
\hline
\end{tabular}

Abbreviations: NA, not available; NC, not classified

${ }^{a}$ no significant increase in cancer risk associated with rs17878362 (TP53 PIN3)

${ }^{\mathrm{b}} P$-value $<0.05$ indicates a Hardy-Weinberg disequilibrium: study exclusion

'Significant increase in cancer risk associated with rs17878362 (TP53 PIN3)

dSame control population

e Same control population

$\mathrm{OR}=1.67,95 \% \mathrm{Cl}=1.02-2.74) \quad($ Table 3 ). A slight but significant increased breast cancer risk was observed in the heterozygous $\mathrm{A} 1 \mathrm{~A} 2$ carriers compared with the $\mathrm{A} 1 \mathrm{~A} 1$ carriers (A1A2 versus $A 1 A 1$ aggregated $O R=1.18,95 \%$ $\mathrm{Cl}=1.02-1.37)$. However, no altered breast cancer risk was seen in the A2A2 carriers (A2A2 versus A1A1 aggregated $\mathrm{OR}=1.41,95 \% \mathrm{Cl}=0.97-2.06)$, although a significant trend towards increased cancer risk was noted as the number of A2 alleles carried was increased $(P$-trend $<0.01)$. No increased risk of lung cancer was observed for any genotype despite the inclusion of 4101 cases and 4052 controls in the analysis (A2A2 versus $\mathrm{A} 1 \mathrm{~A} 1$ aggregated $\mathrm{OR}=1.46,95 \%$ $\mathrm{Cl}=0.71-3.00)$.

Association of rs1042522 and rs1625895 genotypes with cancer susceptibility. Among the 25 selected publications, several have analysed cancer risk associated with the rs1042522 and rs1625895 variant alleles (Table 1). For rs1625895, the 10 studies reporting rs1625895-related ORs showed rs1625895 allele ratios compatible with HardyWeinberg equilibrium, allowing the pooling of 5011 cancer cases and 5100 controls. For the rs 1042522 polymorphism, 8517 cases and 9311 controls were pooled from 17 studies (Supplementary Table 4), while 5 other studies were excluded as the allele ratios for rs1042522 in controls were not compatible with Hardy-Weinberg equilibrium (Table 1). When compared with the respective common homozygous carriers, a small but significant association with cancer risk was observed for heterozygous carriers of the variant allele (rs1042522 R72/P72 versus R72/R72 aggregated $\mathrm{OR}=1.16,95 \% \mathrm{Cl}=1.05-1.18 ; \mathrm{rs} 1625895 \mathrm{GA}$ versus $\mathrm{GG}$ aggregated $\mathrm{OR}=1.19,95 \% \mathrm{Cl}=1.02-1.40$ ) (Supplementary Table 4). However, no increased risk was observed in association with the homozygous carriages of the variant alleles at either position.

\section{Discussion}

A large number of studies have addressed the association of common TP53 polymorphisms with cancer risk (reviewed in Whibley et $a .^{10}$ ). Overall, the reported effects are of small amplitude and many studies have reported contradictory results that may result from many causes: small numbers of cases and controls and thus limited statistical power, the selection of specific tumour types, differences between populations and the lack of reliability in SNP genotyping, in particular in earlier studies. Of the TP53 intronic polymorphisms rs17878362 is the most studied. In this meta-analysis, based on 10786 cases and 11377 controls we detected an aggregated $\mathrm{OR}$ of $1.45(95 \% \mathrm{Cl}=1.22-1.74)$ for increased cancer risk in homozygous carriers of the rare rs17878362 A2 genotype as compared with homozygous carriers of the common A1 genotype. However, no risk was observed when A2A1 carriers were compared with the A1A1 carriers, suggesting that the increased risk associated with rs17878362 follows a recessive model. This result is in 
Table 2 Meta-analysis results for the selected case-control studies focused on the TP53 rs 17878362 polymorphism

\begin{tabular}{|c|c|c|c|c|c|c|}
\hline Genotypes & Cases, $n(\%)$ & Controls, $\boldsymbol{n}(\%)$ & Heterogeneity, $\boldsymbol{P}$-value & OR & $(95 \% \mathrm{Cl})$ & $\boldsymbol{P}$-trend ${ }^{\mathrm{a}}$ \\
\hline \multicolumn{7}{|c|}{ Overall (25 studies, MAF $=0.15)$} \\
\hline Total & $10786(100.0)$ & $11377(100.0)$ & & & & \multirow{4}{*}{$<0.01$} \\
\hline A1A1 & $7639(70.8)$ & $8254(72.5)$ & & 1.00 & - & \\
\hline $\mathrm{A} 1 \mathrm{~A} 2$ & $2823(26.2)$ & $2871(25.2)$ & $0.03^{b}$ & 1.08 & $(0.99-1.18)$ & \\
\hline $\mathrm{A} 2 \mathrm{~A} 2$ & $324(3.0)$ & $252(2.3)$ & $0.06^{b}$ & 1.45 & $(1.22-1.74)$ & \\
\hline \multicolumn{7}{|c|}{ Geographical origin of studies India (study numbers: 1, 2, 4, 5, 6, 22: MAF=0.19) } \\
\hline Total & $1066(100.0)$ & $1133(100.0)$ & & & & \multirow{4}{*}{0.19} \\
\hline A1A1 & $699(65.6)$ & $750(66.2)$ & & 1.00 & - & \\
\hline $\mathrm{A} 1 \mathrm{~A} 2$ & $304(28.5)$ & $345(30.5)$ & $0.54^{\mathrm{c}}$ & 0.94 & $(0.79-1.13)$ & \\
\hline $\mathrm{A} 2 \mathrm{~A} 2$ & $63(5.9)$ & $38(3.3)$ & $0.07^{\mathrm{c}}$ & 1.63 & $(1.10-2.42)$ & \\
\hline \multicolumn{7}{|c|}{ Mediterranean countries (study numbers: $10,13,15,20,21,23: M A F=0.15$ ) } \\
\hline Total & $1213(100.0)$ & $1373(100.0)$ & & & & \multirow{4}{*}{$<0.01$} \\
\hline A1A1 & $806(66.4)$ & $994(72.4)$ & & 1.00 & - & \\
\hline $\mathrm{A} 1 \mathrm{~A} 2$ & $357(29.4)$ & $348(25.4)$ & $0.475^{\mathrm{c}}$ & 1.25 & $(1.03-1.51)$ & \\
\hline $\mathrm{A} 2 \mathrm{~A} 2$ & $50(4.2)$ & $31(2.2)$ & $0.701^{c}$ & 2.54 & $(1.53-4.24)$ & \\
\hline \multicolumn{7}{|c|}{ Northern Europe (study numbers: 7, 8, 11, 17, 19, 24; MAF=0.15) } \\
\hline Total & $4125(100.0)$ & $4716(100.0)$ & & & & \multirow{4}{*}{0.03} \\
\hline A1A1 & $2944(71.4)$ & $3428(72.7)$ & & 1.00 & - & \\
\hline $\mathrm{A} 1 \mathrm{~A} 2$ & $1063(25.8)$ & $1205(25.5)$ & $0.247^{c}$ & 1.05 & $(0.95-1.17)$ & \\
\hline A2A2 & $118(2.8)$ & $83(1.8)$ & $0.795^{\mathrm{c}}$ & 1.70 & $(1.26-2.31)$ & \\
\hline \multicolumn{7}{|c|}{ United States (study numbers: 12, 14, 16, 18, 25; MAF=0.14) } \\
\hline Total & $3963(100.0)$ & $3731(100.0)$ & & & & \multirow{4}{*}{0.65} \\
\hline $\mathrm{A} 1 \mathrm{~A} 1$ & $2947(74.3)$ & $2801(75.0)$ & & 1.00 & - & \\
\hline $\mathrm{A} 1 \mathrm{~A} 2$ & $938(23.7)$ & 849 (22.8) & $0.003^{b}$ & 1.09 & $(0.87-1.38)$ & \\
\hline $\mathrm{A} 2 \mathrm{~A} 2$ & $78(2.0)$ & $81(2.2)$ & $0.344^{c}$ & 1.02 & $(0.73-1.43)$ & \\
\hline
\end{tabular}

Abbreviations: $\mathrm{Cl}$, confidence interval; MAF, minor allele frequency; OR, odds ratio

aFisher's exact test

${ }^{b}$ Heterogeneity $P$-value $\leq 0.05$ : performed random model for meta-analysis

${ }^{c}$ Heterogeneity $P$-value $>0.05$ : performed fixed model for meta-analysis

Table 3 Meta-analysis results for the TP53 rs17878362 polymorphism by cancer type

\begin{tabular}{|c|c|c|c|c|c|c|}
\hline Genotypes & Cases, $n(\%)$ & Controls, $n(\%)$ & Heterogeneity $\boldsymbol{P}$-value & OR & $(95 \% \mathrm{Cl})$ & $P$-trend ${ }^{\mathrm{a}}$ \\
\hline \multicolumn{7}{|c|}{ Breast (Study numbers: 3, 11, 12, 13, 15, 25; MAF=0.17) } \\
\hline Total & $2028(100.0)$ & $1748(100.0)$ & & & & \multirow{4}{*}{$<0.01$} \\
\hline $\mathrm{A} 1 \mathrm{~A} 1$ & $1307(64.5)$ & $1212(69.3)$ & & 1.00 & - & \\
\hline $\mathrm{A} 1 \mathrm{~A} 2$ & $642(31.7)$ & $483(27.6)$ & $0.57^{\mathrm{b}}$ & 1.18 & $(1.02-1.37)$ & \\
\hline $\mathrm{A} 2 \mathrm{~A} 2$ & $79(3.9)$ & $53(3.0)$ & $0.08^{\mathrm{b}}$ & 1.41 & $(0.97-2.06)$ & \\
\hline \multicolumn{7}{|c|}{ Colon (study numbers: $8,17,20,21,23 ; M A F=0.15$ ) } \\
\hline Total & $1637(100.0)$ & $1686(100.0)$ & & & & \multirow{4}{*}{0.08} \\
\hline A1A1 & $1143(69.8)$ & $1214(72.0)$ & & 1.00 & - & \\
\hline $\mathrm{A} 1 \mathrm{~A} 2$ & 453 (27.7) & 444 (26.3) & $0.04^{*}$ & 1.15 & $(0.87-1.50)$ & \\
\hline $\mathrm{A} 2 \mathrm{~A} 2$ & $41(2.5)$ & $28(1.7)$ & $0.33^{\mathrm{b}}$ & 1.67 & $(1.02-2.74)$ & \\
\hline \multicolumn{7}{|c|}{ Lung (study numbers: 18, 19, 25; $M A F=0.13$ ) } \\
\hline Total & $4054(100.0)$ & $4045(100)$ & & & & \multirow{4}{*}{$<0.01$} \\
\hline $\mathrm{A} 1 \mathrm{~A} 1$ & $2977(73.4)$ & 3076 (76.0) & & 1.00 & - & \\
\hline $\mathrm{A} 1 \mathrm{~A} 2$ & 979 (24.2) & 898 (22.2) & $0.02^{*}$ & 1.22 & $(0.96-1.54)$ & \\
\hline A2A2 & $98(2.4)$ & $71(1.8)$ & $0.03^{*}$ & 1.46 & $(0.71-3.00)$ & \\
\hline
\end{tabular}

Abbreviations: $\mathrm{Cl}$, confidence interval; MAF, minor allele frequency; OR, odds ratio

*Heterogeneity $P$-value $\leq 0.05$ : performed random model for meta-analysis

${ }^{a}$ Fisher's exact test

${ }^{b}$ Heterogeneity $P$-value $>0.05$ : performed fixed model for meta-analysis

agreement with the recent meta-analysis of $\mathrm{Hu}$ and collaborators, despite the fact that the two studies differed in the selection and analysis of data to be included as we used original ORs reported in each publication, which was not the case in the study of Hu et al. ${ }^{25,26}$ When sub-grouping data according to tumour site, different associations were seen for breast, colon and lung cancer, which were the only three tumour sites for which over 1600 cases and controls was available with the data drawn from at least three different reports. These differences suggest that the contribution of 
rs17878362 to susceptibility might be different from one tumour type to the other. In the case of breast cancer, the increased risk was associated only with the heterozygosity status. Tumour type heterogeneity, in term of pathology and molecular profiles including the frequency of TP53 mutations, may explain these results although this clearly needs further evaluation. ${ }^{29,30}$ The lack of significant effect in lung cancer might reflect the overwhelming effect of tobacco smoke as a causative risk factor, masking the much smaller contribution of genetic susceptibility factors such as rs 17878362 .

Few studies have investigated the impact of rs 17878362 on cancer susceptibility with respect to the geographical origin of the cohorts. Here, the observed difference across countries could be due to a different distribution in rs17878362 polymorphism between different ethnic groups. Indeed, Sjalander et al. $^{31}$ reported a difference in rs17878362 distribution across latitudes, between Swedish, Asian and Mongolian populations, which is independent of rs1042522 distribution. However, in the present meta-analysis, although some differences in the rs17878362 A2 allele frequency were seen between the different geographical regions, no heterogeneity was observed in the overall data set independently of any geographical consideration. Thus, the difference in rs17878362 A2 allele-related cancer susceptibility in the different countries suggests that additional factors, such as environmental factors, lifestyle and other genetic modifiers, may modulate cancer susceptibility associated with this allele.

Several studies have shown that the rs17878362 polymorphism is in linkage disequilibrium with other common TP53 SNPs, including rs1042522. ${ }^{31,32}$ In a previous study, we have haplotyped rs17878362 and rs1042522 in a group of mostly Caucasian subjects from Brazil and reported that $71 \%$ of the tested population carried the haplotype combining rs17878362 A1 and rs1042522 R72, whereas the haplotype rs17878362 A2/rs1042522 R72 was detected in only $1.5 \%$ of the population. ${ }^{33}$ In contrast, the A1/P72 and A2/P72 haplotypes were almost equally represented (15 and $12.5 \%$ of the population, respectively). This observation suggests that the rs17878362 A2 allele most frequently occurs on a haplotype that also contains rs $1042522 \mathrm{P} 72,{ }^{33}$ raising the possibility that the susceptibility associated with rs 17878362 might be driven, or confounded, by other common TP53 SNPs. To evaluate this possibility, we have used the data compiled from the same set of publications to assessed cancer risk associated with rs1042522 and rs1625895 variants in the same data set. The aggregated ORs for the overall analysis showed that the heterozygote carriers of either variant allele had an increased cancer risk, consistent with several previous meta-analyses. ${ }^{14,25,34}$ However, the effects observed for rs1042522 and rs1625895 were clearly smaller than for rs17878362 and were observed only in heterozygote carriers of rs 1042522 or rs1625895, whereas the effect of rs 17878362 appears to follow a recessive model. This would suggest that if rs1042522 and rs1625895 contribute to susceptibility, this effect could occur independently of their association with rs17878362. These results should be interpreted with caution, as no corrections for multiple testing have been performed. Indeed, it is not possible to calculate the number of tests carried in the original papers in order to correct for multiple comparisons. Moreover, it has to be recognized that this analysis was not designed to specifically assess the cancer risk of these two alleles. The linkage disequilibrium between rs17878362 (tagged by rs2909430, which is in linkage disequilibrium with rs17878362, r2>0.9), rs1042522 and rs1625895 also shows ethnic differences as is reflected in the haplotype frequencies calculated based on published data $^{9}$ for three different HapMap populations (Supplementary Table 5). The most frequently found haplotype in the Caucasian and Asian HapMap populations was found to be rs17878362 A1/ rs1042522 R72/rs1625895 G (78.13\% of the Caucasian and $53.70 \%$ of the Asian population), while this only represented $31.67 \%$ of the haplotypes seen in the African population. The rs17878362 A1/rs1042522 P72/rs1625895 G haplotype was more frequent in the Asian (43.83\%) and African (38.33\%) populations than the Caucasian population (11.46\%), while the rs17878362 A2/rs1042522 P72/rs1625895 A haplotype was seen in only $1.85 \%$ of Asian population compared with 9.37 and $26.11 \%$ of the Caucasian and African populations, respectively. Clearly further studies analysing TP53 haplotypes are needed to clarify the specific contribution of each of these common SNPs to cancer susceptibility.

The mechanistic basis of this altered risk associated with the carriage of the rs17878362 A2 allele is still poorly understood. Some evidence links rs17878362 status to differential expression of different p53 isoforms. In lymphoblastoid cell lines established from breast cancer patients the A1A1 genotype was associated with higher constitutive levels of TP53 mRNA than for the $\mathrm{A} 1 \mathrm{~A} 2$ and $\mathrm{A} 2 \mathrm{~A} 2$ alleles. ${ }^{28}$ Recently, we have shown that TP53 intron 3 is involved in the splicing regulation of the TP53 intron 2, influencing the generation of the fully spliced p53 (FSp53) and the intron-2retaining p53 (p5312) mRNA transcripts. ${ }^{7}$ These transcripts generate the canonical p53 protein and the $\mathrm{N}$-truncated $\Delta 40$ p53 isoform, respectively, the latter being a regulator of p53 activity. ${ }^{8}$ Using in silico algorithms, biophysical measurements and in vitro assays we have shown that the RNA sequences present in TP53 intron 3 pre-RNA can form G-quadruplex structures, whose stability alters the balance of FSp53/p53I2 mRNA species through the modulation of intron 2 splicing. ${ }^{7}$ On the basis of the same in silico algorithms, it appears that the rs17878362 duplication may alter the topology of the G4 structures in intron 3 that may impact on the $\mathrm{FSp53/p53I2} \mathrm{balance.} \mathrm{As} \mathrm{the} \Delta 40 \mathrm{p} 53$ isoform encoded by the p53I2 mRNA can inhibit p53 transcriptional activity and growth suppressive activity in vitro and appears to represent the main form of p53 expressed in mouse embryonic stem cells. ${ }^{2,35-37}$ It is possible that the presence of the rs17878362 A2 variant allele could impact on p53 regulatory activity through the modulation of TP53 mRNA transcript patterns, subsequent isoform expression and maintenance of stem cell-like phenotype. Recent evidence suggesting that mRNA encoding $\triangle 40 p 53$ and $\Delta 133 p 53$ isoforms are over-expressed in some forms of ovarian carcinoma is in support of the hypothesis that changes in expression of these isoforms may contribute to carcinogenesis. ${ }^{38}$ The mechanism by which the rs17878362 polymorphism modulates cancer risk needs to be fully addressed in appropriate functional genetics studies. 


\section{Materials and methods}

Literature search and selection criteria. Publications relative to the association between the rs17878362 polymorphism and cancer risk examined in case-control studies were identified using two databases: Pubmed Central (NCBI, $\mathrm{NIH}$ ) (http://www.nml.ncbi.gov/pubmed) and Web of Science (Thomson Reuters) (http://apps.webofknowledge.com). The publication search was carried out from June 1993, when rs 17878362 was first described ${ }^{20}$ to December 2011. Several individual search terms, as well as combinations, were used: 'TP53', 'p53', 'intron3', 'rs17878362', 'polymorphism', 'intron', 'PIN3' and '16bp-Del', as in several publications the major A1 allele is referred to as a deletion of the $16 \mathrm{bp}$ sequence. The publications were reviewed to identify those that met the following inclusion criteria: (i) that the publication reported a formal case-control study analysing cancer susceptibility associated with rs 17878362 , (ii) results were given as an OR and (iii) the publication was in English.

Statistical analysis. The methodological approach described by Thakkinstian and collaborators was used to carry out our analyses on the association of the rs17878362 polymorphism with cancer risk variant allele with cancer risk and also those on rs 1042522 and rs 1625895 when data were available in the same panel of selected studies. ${ }^{28}$ First, data from both controls and cases were extracted from the selected studies for the TP53 polymorphisms of interest, including the number of subjects, ORs ${ }^{11}$ and the corresponding $95 \% \mathrm{Cls}$ (Table 1 and Supplementary Table 1). Second, the Hardy-Weinberg equilibrium was tested by $\chi^{2}$ goodness of fit in each study. Third, heterogeneity was determined using the $Q$-test and was considered as present when $Q$-test $P$-value was $<0.05$. According to the $Q$-test $P$-value, the association between a polymorphism and cancer risk was investigating using either the fixed- or the random-effects models, according to the method of DerSimonian and Laird. ${ }^{39}$ Using the same methodology, sub-group analyses were performed by geographic location of the population and cancer type. Sensitivity analyses were conducted to assess the impact of any single study (leave-one-out analysis, cumulative inclusion over time analysis). Publication bias was tested using the Egger test. Statistical analyses were performed using the commercial STATA software (version 11.1, StataCorp LP, College Station, Texas, USA).

\section{Conflict of Interest}

The authors declare no conflict of interest.

Acknowledgements. This work was supported by the Institut National Contre le Cancer (INCA), France (2009-192 to JH and PH). Research in Inserm U612 is also supported by funding from Institut Curie and Inserm. CS has a PhD fellowship from the French Ministry of Research and VM's stay in U612 was supported by funding from EU FP7 (Grant Number 249689 for the network of excellence DoReMi (low dose research towards multidisciplinary integration)).

1. Hainaut $\mathrm{P}$, Hollstein M. $\mathrm{p} 53$ and human cancer: the first ten thousand mutations. $A d v$ Cancer Res 2000; 77: 81-137.

2. Petitjean $A$, Mathe $E$, Kato $S$, Ishioka $C$, Tavtigian SV, Hainaut $P$ et al. Impact of mutant p53 functional properties on TP53 mutation patterns and tumor phenotype: lessons from recent developments in the IARC TP53 database. Hum Mutat 2007; 28: 622-629.

3. Levine AJ. p53, the cellular gatekeeper for growth and division. Cell 1997; 88: 323-331.

4. Levine AJ, Oren M. The first 30 years of p53: growing ever more complex. Nat Rev Cancer 2009; 9: 749-758.

5. Meek DW, Anderson CW. Posttranslational modification of $\mathrm{p53}$ : cooperative integrators of function. Cold Spring Harb Perspect Biol 2009; 1: a000950.

6. Vilborg A, Wilhelm MT, Wiman KG. Regulation of tumor suppressor p53 at the RNA level. J Mol Med 2010; 88: 645-652.

7. Marcel V, Tran PL, Sagne C, Martel-Planche G, Vaslin L, Teulade-Fichou MP et al. G-quadruplex structures in TP53 intron 3: role in alternative splicing and in production of p53 mRNA isoforms. Carcinogenesis 2011; 32: 271-278.

8. Marcel V, Dichtel-Danjoy ML, Sagne C, Hafsi H, Ma D, Ortiz-Cuaran S et al. Biological functions of $p 53$ isoforms through evolution: lessons from animal and cellular models. Cell Death Differ 2011; 18: 1815-1824.

9. Garritano S, Gemignani F, Palmero El, Olivier M, Martel-Planche G, Le Calvez-Kelm F et al. Detailed haplotype analysis at the TP53 locus in p.R337H mutation carriers in the population of Southern Brazil: evidence for a founder effect. Hum Mutat 2010; 31: 143-150.

10. Whibley C, Pharoah PD, Hollstein M. p53 polymorphisms: cancer implications. Nat Rev Cancer 2009; 9: 95-107.
11. Stacey SN, Sulem P, Jonasdottir A, Masson G, Gudmundsson J, Gudbjartsson DF et al. A germline variant in the TP53 polyadenylation signal confers cancer susceptibility. Nat Genet 2011; 43: 1098-1103.

12. Matlashewski GJ, Tuck S, Pim D, Lamb P, Schneider J, Crawford LV. Primary structure polymorphism at amino acid residue 72 of human p53. Mol Cell Biol 1987; 7: 961-963.

13. Sullivan A, Syed N, Gasco M, Bergamaschi D, Trigiante G, Attard M et al. Polymorphism in wild-type p53 modulates response to chemotherapy in vitro and in vivo. Oncogene 2004; 23: 3328-3337.

14. Suspitsin EN, Buslov KG, Grigoriev MY, Ishutkina JG, Ulibina JM, Gorodinskaya VM et al. Evidence against involvement of p53 polymorphism in breast cancer predisposition. Int $J$ Cancer 2003; 103: 431-433.

15. Hiyama T, Yoshihara M, Tanaka S, Chayama K. Genetic polymorphisms and esophageal cancer risk. Int J Cancer 2007; 121: 1643-1658.

16. Koushik A, Platt RW, Franco EL. p53 codon 72 polymorphism and cervical neoplasia: a meta-analysis review. Cancer Epidemiol Biomar Prev 2004; 13: 11-22.

17. Tang NP, Wu YM, Wang B, Ma J. Systematic review and meta-analysis of the association between P53 codon 72 polymorphism and colorectal cancer. Eur J Surg Oncol 2010; 36: $431-438$.

18. Matakidou A, Eisen T, Houlston RS. TP53 polymorphisms and lung cancer risk: a systematic review and meta-analysis. Mutagenesis 2003; 18: 377-385.

19. He XF, Su J, Zhang Y, Huang X, Liu Y, Ding DP et al. Association between the p53 polymorphisms and breast cancer risk: meta-analysis based on case-control study. Breast Cancer Res Tr 2011; 130: 517-529.

20. Lazar V, Hazard F, Bertin F, Janin N, Bellet D, Bressac B. Simple sequence repeat polymorphism within the p53 gene. Oncogene 1993; 8: 1703-1705.

21. Costa S, Pinto D, Pereira D, Rodrigues H, Cameselle-Teijeiro J, Medeiros R et al. Importance of TP53 codon 72 and intron 3 duplication $16 \mathrm{bp}$ polymorphisms in prediction of susceptibility on breast cancer. BMC cancer 2008; 8: 32 .

22. Wang-Gohrke S, Becher H, Kreienberg R, Runnebaum IB, Chang-Claude J. Intron 316 bp duplication polymorphism of $p 53$ is associated with an increased risk for breast cancer by the age of 50 years. Pharmacogenetics 2002; 12: 269-272.

23. Gemignani F, Moreno V, Landi S, Moullan N, Chabrier A, Gutierrez-Enriquez S et al. A TP53 polymorphism is associated with increased risk of colorectal cancer and with reduced levels of TP53 mRNA. Oncogene 2004; 23: 1954-1956.

24. Perfumo C, Bonelli L, Menichini P, Inga A, Gismondi V, Ciferri E et al. Increased risk of colorectal adenomas in Italian subjects carrying the p53 PIN3 A2-Pro72 haplotype. Digestion 2006; 74: 228-235.

25. Hu Z, Li X, Qu X, He Y, Ring BZ, Song E et al. Intron 316 bp duplication polymorphism of TP53 contributes to cancer susceptibility: a meta-analysis. Carcinogenesis 2010; 31: 643-647.

26. Lu PH, Wei MX, Li C, Shen W, Chen MB. Need for clarification of data in a recent metaanalysis about TP53 codon 72 polymorphism and cancer susceptibility. Carcinogenesis 2011; $32: 443$ author reply 444.

27. Malik MA, Sharma K, Goel S, Zargar SA, Mittal B. Association of TP53 intron 3, 16 bp duplication polymorphism with esophageal and gastric cancer susceptibility in Kashmir Valley. Oncol Res 2011; 19: 165-169.

28. Thakkinstian A, McElduff P, D'Este C, Duffy D, Attia J. A method for meta-analysis of molecular association studies. Stat Med 2005; 24: 1291-1306.

29. Denisov EV, Sukhanovskaya TV, Dultseva TS, Malinovskaya EA, Litviakov NV Slonimskaya EM et al. Coordination of TP53 abnormalities in breast cancer: data from analysis of TP53 polymorphisms, loss of heterozygosity, methylation, and mutations. Genet Test Mol Biomarkers 2011; 15: 901-907.

30. Ashton KA, Proietto A, Otton G, Symonds I, McEvoy M, Attia J et al. Polymorphisms in TP53 and MDM2 combined are associated with high grade endometrial cancer. Gynecol Oncol 2009; 113: 109-114.

31. Sjalander A, Birgander R, Kivela A, Beckman G. p53 polymorphisms and haplotypes in different ethnic groups. Hum Hered 1995; 45: 144-149.

32. Beckman G, Birgander R, Sjalander A, Saha N, Holmberg PA, Kivela A et al. Is p53 polymorphism maintained by natural selection? Hum Hered 1994; 44: 266-270.

33. Marcel V, Palmero El, Falagan-Lotsch P, Martel-Planche G, Ashton-Prolla P, Olivier M et al. TP53 PIN3 and MDM2 SNP309 polymorphisms as genetic modifiers in the Li-Fraumeni syndrome: impact on age at first diagnosis. J Med Genet 2009; 46: 766-772.

34. Dahabreh IJ, Linardou H, Bouzika P, Varvarigou V, Murray S. TP53 Arg72Pro polymorphism and colorectal cancer risk: a systematic review and meta-analysis. Cancer Epidemiol, Biomarkers Prev 2010; 19: 1840-1847.

35. Courtois S, Verhaegh G, North S, Luciani MG, Lassus P, Hibner U et al. DeltaN-p53, a natural isoform of p53 lacking the first transactivation domain, counteracts growth suppression by wild-type p53. Oncogene 2002; 21: 6722-6728.

36. Ghosh A, Stewart D, Matlashewski G. Regulation of human $\mathrm{p} 53$ activity and cell localization by alternative splicing. Mol Cell Biol 2004; 24: 7987-7997.

37. Maier B, Gluba W, Bernier B, Turner T, Mohammad K, Guise T et al. Modulation of mammalian life span by the short isoform of p53. Genes Dev 2004; 18: 306-319.

38. Hofstetter G, Berger A, Berger R, Zoric A, Braicu El, Reimer D et al. The N-terminally truncated p53 isoform Delta40p53 influences prognosis in mucinous ovarian cancer. Int $\mathrm{J}$ Gynecol Cancer 2012; 22: 372-379.

39. DerSimonian R, Laird N. Meta-analysis in clinical trials. Controlled Clin Trials 1986; 7: 177-188. 
40. Jha $P$, Jha $P$, Pathak $P$, Chosdol $K$, Suri V, Sharma MC et al. TP53 polymorphisms in gliomas from Indian patients: Study of codon 72 genotype, rs1642785, rs1800370 and 16 base pair insertion in intron-3. Exp Mol Pathol 2011; 90: 167-172.

41. Umar M, Upadhyay R, Khurana R, Kumar S, Ghoshal UC, Mittal B. Role of p53 and p73 genes polymorphisms in susceptibility to esophageal cancer: a case control study in a northern Indian population. Mol Biol Rep 2012; 39: 1153-1162.

42. Alawadi S, Ghabreau L, Alsaleh M, Abdulaziz Z, Rafeek M, Akil N et al. P53 gene polymorphisms and breast cancer risk in Arab women. Med Oncol 2011; 28: 709-715.

43. Mittal RD, George GP, Mishra J, Mittal T, Kapoor R. Role of functional polymorphisms of $\mathrm{P} 53$ and P73 genes with the risk of prostate cancer in a case-control study from Northern India. Arch Med Res 2011; 42: 122-127.

44. Naccarati A, Pardini B, Polakova V, Smerhovsky Z, Vodickova L, Soucek P et al. Genotype and haplotype analysis of TP53 gene and the risk of pancreatic cancer: an association study in the Czech Republic. Carcinogenesis 2010; 31: 666-670.

45. Polakova V, Pardini B, Naccarati A, Landi S, Slyskova J, Novotny J et al. Genotype and haplotype analysis of cell cycle genes in sporadic colorectal cancer in the Czech Republic Hum Mutat 2009; 30: 661-668.

46. De Feo E, Persiani R, La Greca A, Amore R, Arzani D, Rausei S et al. A case-control study on the effect of $p 53$ and $p 73$ gene polymorphisms on gastric cancer risk and progression. Mutat Res 2009; 675: 60-65.

47. Hrstka R, Beranek M, Klocova K, Nenutil R, Vojtesek B. Intronic polymorphisms in TP53 indicate lymph node metastasis in breast cancer. Oncol Rep 2009; 22: 1205-1211.

48. Gaudet MM, Gammon MD, Bensen JT, Sagiv SK, Shantakumar S, Teitelbaum SL et al. Genetic variation of TP53, polycyclic aromatic hydrocarbon-related exposures, and breast cancer risk among women on Long Island, New York. Breast Cancer Res Treat 2008; 108: 93-99.

49. Ye Y, Yang H, Grossman HB, Dinney C, Wu X, Gu J. Genetic variants in cell cycle control pathway confer susceptibility to bladder cancer. Cancer 2008; 112: 2467-2474.

50. De Vecchi G, Verderio P, Pizzamiglio S, Manoukian S, Bernard L, Pensotti V et al. The p53 Arg72Pro and Ins16bp polymorphisms and their haplotypes are not associated with breast cancer risk in BRCA-mutation negative familial cases. Cancer Detect Prev 2008; 32: $140-143$

51. Chen K, Hu Z, Wang LE, Zhang W, El-Naggar AK, Sturgis EM et al. Polymorphic TP53BP1 and TP53 gene interactions associated with risk of squamous cell carcinoma of the head and neck. Clin Cancer Res 2007; 13: 4300-4305.

52. Tan XL, Nieters A, Hoffmeister M, Beckmann L, Brenner H, Chang-Claude J. Genetic polymorphisms in TP53, nonsteroidal anti-inflammatory drugs and the risk of colorectal cancer: evidence for gene-environment interaction? Pharmacogenet Genomics 2007; 17: 639-645.

53. Wang W, Spitz MR, Yang H, Lu C, Stewart DJ, Wu X. Genetic variants in cell cycle control pathway confer susceptibility to lung cancer. Clin Cancer Res 2007; 13: 5974-5981.

54. Hung RJ, Boffetta P, Canzian F, Moullan N, Szeszenia-Dabrowska N, Zaridze D et al. Sequence variants in cell cycle control pathway, X-ray exposure, and lung cancer risk: a multicenter case-control study in Central Europe. Cancer Res 2006; 66 : 8280-8286

55. Mitra S, Sikdar N, Misra C, Gupta S, Paul RR, Roy B et al. Risk assessment of p53 genotypes and haplotypes in tobacco-associated leukoplakia and oral cancer patients from eastern Idia. Int J Cancer 2005; 117: 786-793.

56. Wu X, Zhao H, Amos Cl, Shete S, Makan N, Hong WK et al. p53 Genotypes and Haplotypes Associated With Lung Cancer Susceptibility and Ethnicity. J Natl Cancer Inst 2002; 94: 681-690.

(c) Cell Death and Disease is an open-access journal published by Nature Publishing Group. This work is licensed under the Creative Commons Attribution-NonCommercial-No Derivative Works 3.0 Unported License. To view a copy of this license, visit http://creativecommons.org/licenses/by-nc-nd/3.0/

Supplementary Information accompanies the paper on Cell Death and Disease website (http://www.nature.com/cddis) 